\title{
Effectiveness of Prophylactic Use of Intravenous Ketamine, Dexmedetomidine and Tramadol for Prevention of Shivering After Spinal Anesthesia
}

\author{
Poonam M Vaghela', Madhuri Sureshbhai Vyas ${ }^{2}$ \\ ${ }^{1}$ Assistant Professor, Department of Anaesthesia, GMERS Medical College, Gandhinagar, Gujarat, India, ${ }^{2}$ MD, Anaesthesia, Sola road, Naranpura, \\ Ahmedabad.
}

\section{Abstract}

Background: Shivering after spinal anesthesia is a common complication and can occur in as many as $40 \%-70 \%$ of patients after regional anesthesia. Present study was done with an aim to assess and evaluate the effectiveness of prophylactic use of intravenous (IV) ketamine, dexmedetomidine, and tramadol for prevention of shivering after spinal anesthesia. Subjects and Methods: Present study was conducted at tertiary care institute of Gujarat, India. The study was carried out in 160 patients and the participants were randomized into four groups of 40 patients each as Group A - patients receiving ketamine $0.5 \mathrm{mg} / \mathrm{kg}$ intravenous (IV) diluted in $10 \mathrm{~mL}$ of normal saline (NS) given as IV infusion over $10 \mathrm{~min}$ Group B - patients receiving tramadol $0.5 \mathrm{mg} / \mathrm{kg}$ diluted in $10 \mathrm{~mL}$ of NS given as IV infusion over $10 \mathrm{~min}$, Group C patients receiving dexmedetomidine $0.5 \mathrm{mcg} / \mathrm{kg}$ diluted in $10 \mathrm{~mL}$ of NS given as IV infusion over $10 \mathrm{~min}$, Group D - patients receiving $10 \mathrm{~mL}$ of NS given as IV infusion over $10 \mathrm{~min}$. Results: There was no statistically significant difference among mean age, gender, and the duration of surgery. There was statistically significant difference among the four groups, when overall shivering grades were compared. The overall sedation score, when compared among four groups was statistically significant. Conclusion: Dexmedetomidine is effective and comparably better than tramadol or ketamine in preventing shivering after spinal anesthesia. Apart from preventing shivering, dexmedetomidine offers other advantages in the form of sedation without any respiratory depression. However, with its use a watch should be kept on the fall hemodynamic parameters.

Keywords: Dexmedetomidine, Sedation, Shivering, Spinal anesthesia.

Corresponding Author: Madhuri Sureshbhai Vyas, 25/292, aakashganga apartment, Sola road, Naranpura, Ahmedabad-380063.

Received: March 2019

Accepted: March 2019

\section{Introduction}

Shivering after spinal anesthesia is a common complication and can occur in as many as $40 \%-70 \%$ of patients after regional anesthesia. This shivering, apart from its physiological and hemodynamic effects, has been described as even worse than surgical pain. It occurs frequently after anesthesia, and the mechanisms leading to shivering remain poorly understood. ${ }^{[1]}$ Shivering, apart from causing discomfort to the patient increases oxygen demand, hampers patient monitoring, increases catecholamine levels subjecting the patient to a higher risk of cardiovascular complications and increases intracranial and intraocular pressure. ${ }^{[2-4]}$ Apart from discomfort, postanaesthetic shivering may be associated with increased oxygen consumption, carbon dioxide output and minute ventilation, ${ }^{[5]}$ catecholamine release, increased cardiac output, tachycardia and hypertension, and increased intraocular pressure.6 Shivering may also decrease mixed venous oxygen saturation and may also interfere with monitoring. ${ }^{[7,8]}$

Shivering is uncomfortable for the patients and has been reported worse than the surgical pain. Shivering may aggravate postoperative pain by stretching the surgical incision. The increase in metabolic requirement may predispose to difficulties in patients with existing intrapulmonary shunts, patients with fixed cardiac output states, or those with limited respiratory reserves. Both, the prevention of shivering and the treatment of established shivering should be attempted in the perioperative period. Anesthesiologists may therefore wish to prevent shivering by using pharmacological strategies in selected surgical patients. ${ }^{[9]}$

Various pharmacologic agents that have been used for prophylaxis and treatment of postspinal shivering range from opioids like fentanyl, tramadol meperidine, anticholinergics physostigmine, analgesic nefopam, N-methyl-d-aspartate (NMDA) receptor antagonist ketamine, 8 and the latest being $\alpha 2$ blockers clonidine and dexmedetomidine. ${ }^{[10-15]}$ Present study was done with an aim to assess and evaluate the effectiveness of prophylactic use of intravenous (IV) ketamine, dexmedetomidine, and tramadol for prevention of shivering after spinal anesthesia. 


\section{Subjects and Methods}

Present study was conducted at tertiary care institute of Gujarat, India. Ethical approval was taken from the institutional ethical committee and written informed consent was taken from all of the participants. Patients in the American Society of Anaesthesiologists (ASA) physical status Class I or II, aged 19-65 years and planned for lower limb surgeries under spinal anesthesia were included in the study. Exclusion criteria were patients who were not willing to participate and those who had systemic diseases. The study was carried out in 160 patients and the participants were randomized into four groups of 40 patients each as Group A - patients receiving ketamine $0.5 \mathrm{mg} / \mathrm{kg}$ intravenous (IV) diluted in $10 \mathrm{~mL}$ of normal saline (NS) given as IV infusion over $10 \mathrm{~min}$ Group B - patients receiving tramadol $0.5 \mathrm{mg} / \mathrm{kg}$ diluted in $10 \mathrm{~mL}$ of NS given as IV infusion over $10 \mathrm{~min}$, Group $\mathrm{C}$ - patients receiving dexmedetomidine $0.5 \mathrm{mcg} / \mathrm{kg}$ diluted in $10 \mathrm{~mL}$ of NS given as IV infusion over $10 \mathrm{~min}$, Group D - patients receiving 10 $\mathrm{mL}$ of NS given as IV infusion over $10 \mathrm{~min}$. The infusion was administered just before administering the spinal anesthesia.

On arrival of the patient in the operating room, a peripheral IV access was obtained using an $18 \mathrm{G}$ venous cannula. All the ASA monitoring standards were followed including heart rate, electrocardiogram, noninvasive blood pressure, saturation of hemoglobin with oxygen (SpO2), and temperature monitoring. Baseline reading of all the parameters was noted. IV fluids were preheated to $37^{\circ} \mathrm{C}$ in a warmed cabinet and given without in-line warming. Lactated Ringer's solution warmed to $37^{\circ} \mathrm{C}$ was infused at $10 \mathrm{~mL} / \mathrm{kg} / \mathrm{h}$ over 30 min just before spinal anesthesia was administered. The infusion rate was thereafter reduced to $6 \mathrm{~mL} / \mathrm{kg} / \mathrm{h}$ till the end of surgery. Study drug was coded and given as IV infusion over $10 \mathrm{~min}$ just before giving the neuraxial block by an anesthesiologist not involved in the management of the patient. Spinal anesthesia was instituted at L3-4 or L 4-5 interspace with patient in lateral position with $2.8 \mathrm{~mL}(14$ $\mathrm{mg}$ ) of bupivacaine (heavy) $0.5 \%$ using a $25 \mathrm{G}$ Quincke's spinal needle. Temperature (core and surface), heart rate, systolic blood pressure, diastolic blood pressure and mean arterial pressure (MAP), peripheral oxygen saturation $(\mathrm{SpO} 2)$ and level of sensory block were assessed before intrathecal injection and thereafter at $5 \mathrm{~min}$ intervals. Sensory block was assessed every $5 \mathrm{~min}$ intervals till there was no change in the level of anesthesia. The ambient temperature was measured by a wall thermometer and was maintained at $24^{\circ} \mathrm{C} \pm 1^{\circ} \mathrm{C}$.

All the patients were draped using a single layer of surgical drapes for the surgery. The presence of shivering was observed and graded from 0 to 4 using a scale, where 0 indicated no shivering and 4 indicated shivering all over the body. The degree of sedation was assessed according to Ramsay sedation score, where a score of 1 indicated that the patient is anxious and agitated or restless or both, and a highest score of 6 indicated that the patient exhibits no response. Hypotension was treated by increasing the rate of IV fluid from $6 \mathrm{~mL} / \mathrm{kg} / \mathrm{h}$ to $10 \mathrm{~mL} / \mathrm{kg} / \mathrm{h}$, and if required, with an IV incremental bolus dose of mephentermine $3 \mathrm{mg}$.
Symptomatic bradycardia was managed with $0.6 \mathrm{mg}$ of injection atropine given IV.

\section{Statistical analysis}

The data was coded and entered into Microsoft Excel spreadsheet. Analysis was done using SPSS version 15 (SPSS Inc. Chicago, IL, USA) Windows software program. The variables were assessed for normality using the Kolmogorov-Smirnov test. Descriptive statistics were calculated.

\section{Results}

There was no statistically significant difference among mean age, gender, and the duration of surgery. For most of the observations, while comparing the mean heart rate, there was a statistically significant difference among the groups throughout the duration of surgery. This difference in the mean heart rate can be explained by the physiological effects of these drugs on the cardiovascular system. The four groups were comparable as regard the mean systolic blood pressures at $0 \mathrm{~min}$ and $5 \mathrm{~min}$. This difference was, however, statistically significant at all other times. There was statistically significant difference among the groups, when they were compared on the variables of mean diastolic blood pressure and mean MAP. The increase in mean surface temperature for the duration of observation was minimal in Group C.

The overall incidence of shivering in all four groups combined was $39.9 \%$. [Table 1] There was statistically significant difference among the four groups, when overall shivering grades were compared The incidence of shivering in Group A was $44.5 \%$, Group B was $47.5 \%$, Group C was $40.2 \%$ and Group D was $21 \%$. The overall sedation score, when compared among four groups was statistically significant. No patient had sedation scores of 5 and 6 on sedation scale in any group. [Table 2]

Table 1: Comparison of grade of shivering among study participants

\begin{tabular}{|l|l|l|l|l|l|l|l|}
\hline \multirow{2}{*}{ Groups } & Grade of Shivering & \multirow{2}{*}{ Total } & \multirow{2}{*}{ P value } \\
\cline { 2 - 6 } & $\mathbf{0}$ & $\mathbf{1}$ & $\mathbf{2}$ & $\mathbf{3}$ & $\mathbf{4}$ & & \\
\hline Group A & 22 & 4 & 6 & 3 & 5 & 40 & \multirow{2}{*}{$0.03^{*}$} \\
\hline Group B & 20 & 4 & 6 & 5 & 5 & 40 & \\
\hline Group C & 24 & 4 & 6 & 2 & 4 & 40 & \\
\hline Group D & 28 & 5 & 3 & 1 & 3 & 40 & \\
\hline
\end{tabular}

Table 2: Comparison of sedation scores among study participants

\begin{tabular}{|c|c|c|c|c|c|c|c|}
\hline \multirow[t]{2}{*}{ Groups } & \multicolumn{5}{|c|}{ Grade of Shivering } & \multirow[t]{2}{*}{ Total } & \multirow[t]{2}{*}{$P$ value } \\
\hline & $\mathbf{0}$ & 1 & 2 & 3 & 4 & & \\
\hline Group A & 0 & 4 & 24 & 10 & 2 & 40 & \multirow{4}{*}{$0.03 *$} \\
\hline Group B & 1 & 6 & 29 & 3 & 1 & 40 & \\
\hline Group C & 1 & 8 & 27 & 2 & 2 & 40 & \\
\hline Group D & 0 & 1 & 20 & 15 & 4 & 40 & \\
\hline
\end{tabular}

$*$ indicates statistically significance at $\mathrm{p} \leq 0.05$

\section{Discussion}

The incidence of shivering under regional anesthesia has been reported to be as high as $56 \%$. The pharmacological 
armamentarium against shivering ranges from opioids like fentanyl, tramadol meperidine, anticholinergics physostigmine, analgesic nefopam, NMDA receptor, antagonist ketamine, and the latest being $\alpha 2$ blockers clonidine and dexmedetomidine. ${ }^{[10-15]}$ The choice of agent depends on the sedative properties and the adverse effect profile of the drug, thereby facilitating early recovery and discharge of the patient. Perioperative shivering occurs as a thermoregulatory response to hypothermia. However, in the postoperative period, shivering may occur even with normothermia, which suggests that mechanisms other than heat loss and subsequent decrease in core temperature may lead to shivering. The patient recovery in the postoperative period may suffer because of shivering. Shivering by itself may aggravate postoperative pain, by stretching the surgical incision. ${ }^{[17,18]}$

Pharmacological agents such as ketamine and tramadol have been in use since long as agents for prevention and treatment of postanaesthetic shivering, however, dexmedetomidine's role in prevention of shivering has not been studied much. Dexmedetomidine acts by blocking $\alpha 2$ receptors at the locus ceruleus of the brainstem and spinal cord thus causing sedation and analgesia. The mechanism for antishivering and diuretic actions is yet to be established. Ketamine causes sympathetic stimulation and vasoconstriction in patients at risk of hypothermia. Ketamine may control shivering by nonshivering thermogenesis either by its effects on the hypothalamus, or by the $\alpha$-adrenergic effect of norepinephrine. Tramadol is an opioid analgesic with its actions preferably mediated via $\mu$ receptor with minimal effect on $\kappa$ and $\delta$ receptors. However, it has may have adverse effects in the form of nausea, vomiting, and dizziness which may cause further discomfort to the patient. ${ }^{[19,20]}$

There was less shivering in Group $\mathrm{C}$ as compared to other groups. This might be due to higher sedative effects of dexmedetomidine, or it is possible that there are some other mechanisms responsible for anti-shivering properties of dexmedetomidine. The changes in surface temperatures, apart from fall in core temperatures may also contribute to shivering.

The percentage of patients requiring treatment of in the form increasing the rate of IV fluids from $6 \mathrm{~mL} / \mathrm{kg} / \mathrm{h}$ to 10 $\mathrm{mL} / \mathrm{kg} / \mathrm{h}$, and injection mephentermine were $47 \%$ in Group A, $51 \%$ in Group B, 53\% in Group C, and $89 \%$ in Group D. The difference among the groups was statistically significant. However, the fall in MAP in Group D stabilized after a single dose of mephentermine in most cases, and subsequent doses were not required. The results of the study are comparable to the results of the study done by Bozgeyik et al. where the authors have concluded that preemptive tramadol and dexmedetomidine are effective in preventing shivering after spinal anesthesia. Dexmedetomidine also provided sedation which is sufficient to prevent the anxiety without any adverse effects. ${ }^{[21]}$ Usta et al. reported effective prevention of shivering and adequate sedation with the use of dexmedetomidine infusion in patients during spinal anesthesia. $^{[22]}$

Prophylaxis of postoperative shivering with simple pharmacological interventions is possible and is clinically effective; however, prophylaxis may be useful in certain specific patient population like the patients with compromised cardiac supply. In these patients it may be worthwhile to give an antishivering drug prophylactically, and dexmedetomidine may be a good choice in these patients, because in addition to its antishivering effect, it has favorable effect on cardiac outcome and provides adequate sedation.

\section{Conclusion}

Dexmedetomidine is effective and comparably better than tramadol or ketamine in preventing shivering after spinal anesthesia. Apart from preventing shivering, dexmedetomidine offers other advantages in the form of sedation without any respiratory depression. However, with its use a watch should be kept on the fall hemodynamic parameters.

\section{References}

1. De Witte J, Sessler DI. Perioperative shivering: Physiology and pharmacology. Anesthesiology 2002;96:467-84.

2. Bhattacharya P, Bhattacharya L. Postanaesthetic shivering (PAS): A review. Indian J Anaesth 2003;47:88-93.

3. Buggy DJ, Crossley AW. Thermoregulation, mild perioperative hypothermia and postanaesthetic shivering. Br J Anaesth 2000;84:61528.

4. Chan AM, Ng KF, Tong EW, Jan GS. Control of shivering under regional anesthesia in obstetric patients with tramadol. Can J Anaesth 1999;46:253-8

5. Ehrenström Reiz R. NA GM, Reiz SL. EMLA-a eutectic mixture of local anesthetics for topical anaesthesia. Acta Anaesthesiol Scand. 1982 Dec;26(6):596-8

6. Giovannetti JA, Bennet CR. Assessment of allergy to local anesthetics. Am Dent Assoc. 1979;98:701-6.

7. Scott J, Huskisson EC. Vertical or horizontal visual analogue scales. Ann Rheumatic Dis. 1979 Dec 1;38(6):560.

8. Daneshkazemi A, Abrisham SM, Daneshkazemi P, Davoudi A. The efficacy of eutectic mixture of local anesthetics as a topical anesthetic agent used for dental procedures: a brief review. Anesthesia Essays Res. 2016 Sep;10(3):383.

9. Gangopadhyay S, Gupta K, Acharjee S, Nayak S, Dawn S, Piplai G. Ketamine, tramadol and pethidine in prophylaxis of shivering during spinal anaesthesia. J Anaesthesiol Clin Pharmacol 2010;26:59-63.

10. Guffin A, Girard D, Kaplan JA. Shivering following cardiac surgery: Hemodynamic changes and reversal. J Cardiothorac Anesth 1987;1:248 .

11. Buggy DJ, Crossley AW. Thermoregulation, mild perioperative hypothermia and postanaesthetic shivering. Br J Anaesth 2000;84:61528.

12. de Courcy JG. Artefactual 'hypotension' from shivering. Anaesthesia 1989;44:787-8.

13. Kranke P, Eberhart LH, Roewer N, Tramèr MR. Single-dose parenteral pharmacological interventions for the prevention of postoperative shivering: A quantitative systematic review of randomized controlled trials. Anesth Analg 2004;99:718-27.

14. Sharma DR, Thakur JR. Ketamine and shivering. Anaesthesia 1990;45:252-3.

15. Dal D, Kose A, Honca M, Akinci SB, Basgul E, Aypar U. Efficacy of prophylactic ketamine in preventing postoperative shivering. $\mathrm{Br} \mathrm{J}$ Anaesth 2005;95:189-92.

16. Kose EA, Honca M, Dal D, Akinci SB, Aypar U. Prophylactic ketamine to prevent shivering in parturients undergoing Cesarean delivery during spinal anesthesia. J Clin Anesth 2013;25:275-80.

17. Shukla U, Malhotra K, Prabhakar T. A comparative study of the effect of clonidine and tramadol on post-spinal anaesthesia shivering. Indian $\mathrm{J}$ Anaesth 2011;55:242-6.

18. Sessler DI. Temperature regulation and monitoring. In. Miller RD, 
editor. Anesthesia. 7th ed. New York: Churchill Livingstone, Elsevier; 2010. p. 1533-56.

19. Talke P, Tayefeh F, Sessler DI, Jeffrey R, Noursalehi M, Richardson C. Dexmedetomidine does not alter the sweating threshold, but comparably and linearly decreases the vasoconstriction and shivering thresholds. Anesthesiology 1997;87:835-41.

20. Mittal G, Gupta K, Katyal S, Kaushal S. Randomised double-blind comparative study of dexmedetomidine and tramadol for post-spinal anaesthesia shivering. Indian J Anaesth 2014;58:257-62.

21. Bozgeyik S, Mizrak A, Kiliç E, Yendi F, Ugur BK. The effects of preemptive tramadol and dexmedetomidine on shivering during arthroscopy. Saudi J Anaesth 2014;8:238-43.

22. Usta B, Gozdemir M, Demircioglu RI, Muslu B, Sert H, Yaldiz A. Dexmedetomidine for the prevention of shivering during spinal anesthesia. Clinics (Sao Paulo) 2011;66:1187-91.

Copyright: ( $\odot$ the author(s), publisher. Academia Anesthesiologica International is an Official Publication of "Society for Health Care \& Research Development". It is an open-access article distributed under the terms of the Creative Commons Attribution Non-Commercial License, which permits unrestricted non-commercial use, distribution, and reproduction in any medium, provided the original work is properly cited.

How to cite this article: Vaghela PM, Vyas MS. Effectiveness of Prophylactic Use of Intravenous Ketamine, Dexmedetomidine and Tramadol for Prevention of Shivering After Spinal Anesthesia. Acad. Anesthesiol. Int. 2019;4(1):67-70.

DOI: dx.doi.org/10.21276/aan.2019.4.1.15

Source of Support: Nil, Conflict of Interest: None declared. 